Running Head: Antecedents of Perceived Coach Support

\title{
Applying Generalizability Theory to Examine the Antecedents of Perceived Coach Support
}

\author{
${ }^{1}$ Adam, H. Coussens*, ${ }^{1}$ Tim Rees, and ${ }^{2}$ Paul Freeman \\ ${ }^{1}$ Sport and Health Sciences, University of Exeter \\ ${ }^{2}$ School of Biological Sciences, University of Essex
}

*Address correspondence to Adam Coussens, Sport and Health Sciences, University of Exeter, St Luke’s Campus, Heavitree Road, UK, EX1 2LU. Email address: ahc205@exeter.ac.uk,or acuzz39@hotmail.com

Manuscript accepted for publication in Journal of Sport \& Exercise Psychology on December 6th, 2014 
Applying Generalizability Theory to Examine the Antecedents of Perceived Coach Support 


\begin{abstract}
Although social support is integral to the coaching process, there is only a limited understanding of the antecedents of perceived coach support. We applied generalizability theory to examine perceived coach support and its antecedents at perceiver, provider, and relational levels of analysis. Two studies were conducted in which athletes rated the degree to which they identified with a selection of coaches, and the personality, competency, and supportiveness of those coaches. Univariate analyses demonstrated that the relational component accounted for a significant amount of variance in perceived coach support in both studies. Multivariate analyses demonstrated that when athletes perceive specific coaches to be highly agreeable, competent, and individuals with whom they share a common identity, they also perceive these same coaches to be particularly supportive in comparison to other coaches.
\end{abstract}

Keywords: coach-athlete relationship, coach competency, personality, social identity, social support 


\section{Applying Generalizability Theory to Examine the Antecedents of Perceived}

\section{Coach Support}

Social networks are crucial to our health, well-being, and the learning and transfer of skills (Bolger, Foster, Amiram, \& Ng, 1996; Chiaburu, van Dam, \& Hutchins, 2010; Cohen \& Janicki-Deverts, 2009; Ertel, Glymour, \& Berkman, 2009; Thoits, 2011; Uchino, 2004; Umberson \& Montez, 2010). It is, therefore, not surprising that social support has been recognized as a key factor for the success and well-being of athletes (Bianco \& Eklund, 2001; Connaughton, Wadey, Hanton, \& Jones, 2008; DeFreese \& Smith, 2013; Fletcher \& Sarkar, 2012; Kristiansen \& Roberts, 2010; Rees \& Hardy, 2000). Social support is also integral to the coaching process (Antonini Philippe \& Seiler, 2006; Chelladurai \& Saleh, 1980; Kristiansen \& Roberts, 2010; Mageau \& Vallerand, 2003), and coaches are key providers of support (Bianco, 2001; Rosenfeld, Richman, \& Hardy, 1989). Thus, examining the antecedents of perceptions of coach support is vital for sport psychology. At present, we have only a limited understanding of this process. The current research addresses this lacuna in two studies that examine the influence of coach personality, coach competency, and shared identity on perceptions of coach support.

Social support is comprised of three key constructs: social integration, perceived support, and received support (Lakey, 2010). Social integration refers to the structure and quantity of social relationships (Schwarzer \& Knoll, 2007), perceived support refers to appraisals of support availability (Vangelisti, 2009), and received support refers to the type or amount of support obtained from social networks (Vangelisti, 2009). Perceived and received support are distinct but related concepts (Haber, Cohen, Lucas, \& Baltes, 2007), and can have different effects on athlete outcomes. Indeed, while effects for received support are inconsistent (e.g., see Uchino, 2004, 2009), those for perceived support suggest that this type of support is consistently associated with positive outcomes, such as performance (Freeman 
\& Rees, 2008; Freeman \& Rees, 2009; Gillet, Vallerand, Amoura, \& Baldes, 2009), selfconfidence (Rees \& Freeman, 2007), and flow states (Bakker, Oerlemans, Demerouti, Slot, \& Ali, 2011; Rees, Ingledew, \& Hardy, 1999). Further, supportive coaches have been found to help athletes during career transitions (Stambulova, Alfermann, Statler, \& Côté, 2009), injury rehabilitation (Judge et al., 2012), and to promote self-determined behaviors in their athletes (Alvarez, Balaguer, Castillo, \& Duda, 2009). Given this evidence, it is vital to understand what influences perceptions of coach support.

\section{Generalizability Theory}

One way to understand the determinants of perceived coach support is to draw on generalizability theory. Generalizability theory was developed as a statistical method to examine the reliability of behavioral measurements, and extends classical test theory by accounting for multiple sources of error (Cronbach, Gleser, Nanda, \& Rajaratnam, 1972). Conceptually, generalizability theory is similar to the Social Relations Model (Kenny, 1994), and it has subsequently been applied to provide vital insight into the extent to which perceptions of support are influenced by individual and social factors (Lakey \& Orehek, 2011). Such insight is crucial to advance understanding of how support perceptions are formed, the consistency of individuals' support perceptions across different providers, and will ultimately contribute to the development of social support theory and the design of effective support interventions. Applied to the present context, univariate generalizability theory provides a method that partitions variance in perceived coach support into three such components: perceiver, provider, and relational. The perceiver component reflects a traitlike tendency for athletes to vary in how they perceive coaches. For example, athlete A may perceive all coaches as very supportive, whereas athlete B may perceive all coaches as unsupportive. The provider component reflects the extent to which athletes agree in their perception of the supportiveness of certain coaches. For example, all athletes may agree that 
one coach is more supportive than another coach. The relational component reflects athletes' personal taste in rating certain coaches as supportive. For example, one athlete may rate coach A to be more supportive than coach B, whereas another athlete may rate coach B to be more supportive than coach A.

Rees and colleagues (Rees, Freeman, Bell, \& Bunney, 2012) recently used a generalizability theory approach to examine perceptions of coach support. In three independent samples, athletes rated the supportiveness of five well-known managers from the English Premier League (Study 1), five coaches who described their coaching style in brief videos (Study 2), or five coaches who they had worked with on a gifted and talented program (Study 3). Regardless of whether athletes had actually interacted with the coaches (Study 3) or not (Studies 1 and 2), the relational component consistently accounted for the greatest amount of variance in perceived coach support (29\% - 41\%), in comparison to the provider component (10\% - 29\%) and perceiver component (20\% - 22\%). This evidence suggests that athletes may systematically disagree in their perceptions of the supportiveness of coaches. Such findings mirror those from social psychology (Lakey \& Orehek, 2011). A recent review of five studies in which perceivers from non-athletic samples judged the supportiveness of members of their own social networks found that the relational component was the key component of perceived support, accounting on average for $62 \%$ of the variance in perceived support, in comparison to $27 \%$ for the perceiver component, and $7 \%$ for the provider component (Lakey, 2010).

Although this evidence speaks to the importance of understanding that perceptions of coach support are far from universal, it raises the question as to what underpins these effects. That is, why do some athletes disagree on the supportiveness of certain coaches? What influences athletes’ support perceptions? These questions are important for a full understanding of the coach-athlete support process, and can be answered with an extension to 
the previous analyses. In the present research, therefore, in addition to re-examining the components of perceived coach support in two new samples using univariate generalizability theory, we extended this work by examining antecedents of perceived coach support across the three components using multivariate generalizability theory. As an extension of univariate generalizability theory, multivariate generalizability theory allows an examination of the relationships between hypothesized predictors and perceived coach support at perceiver, provider, and relational levels. To our knowledge, this approach has not been applied before to examine these effects in sport. As perceiver, provider, and relational components are conceptually distinct, the links between perceived coach support and its antecedents could differ across components (Lakey, 2010). For example, Lakey, Cohen and Neely (2008) found that perceived similarity and perceived support were significantly correlated at the relational level, but not at the perceiver or provider levels. In the present research, we focused on the influence of coach personality, coach competency, and a shared social identity as potential antecedents of perceived coach support.

Intuitively it might be assumed that perceptions of support are derived from the quantity and quality of support received from a provider (Lakey, Drew, \& Sirl, 1999; Rees et al., 2012), but perceived and received support are only moderately related (Haber et al., 2007). In contrast, social-cognitive explanations suggest that individuals base perceptions of support on either generic evaluations of the providers or their specific traits (Lakey \& Drew, 1997). Indeed, empirical evidence in social psychology suggests that the personality of providers is an important predictor of perceived support (Lakey et al., 1999; Lakey et al., 2004; Lutz \& Lakey 2001). This relationship appears robust regardless of whether providers and perceivers are long-standing dyads (Lakey et al., 2002) or have never interacted (Lakey et al., 2004). For example, Lakey et al. (2004) asked participants to rate popular television characters as potential support providers and found significant correlations between ratings of 
the providers' personalities and perceived support at the provider and relational level of analysis. In sport, Smoll and Smith (1989) also argued that coaches' personalities might influence how they are viewed by athletes. It, therefore, seems reasonable to examine whether coach personality is associated with perceived coach support.

Coaches' experience, reputations, and qualifications are among the most important factors that athletes consider when making judgments about them (Manley, Greenlees, Thelwell, Filby, \& Smith, 2008), and coach competency plays an important role in the development of coach-athlete relationships (Horn, 2002; Thelwell, Weston, Greenlees, Page, \& Manley, 2010). Similarly, the knowledge and expertise of support providers underpins the effectiveness of support (Gottlieb, 2000; Rosenfeld et al., 1989). As such, the competency of a coach may be a key concept from which athletes form perceptions of coach supportiveness, with highly competent coaches being viewed as well qualified to provide support if it is required.

The development of supportive relationships may also be influenced by the extent to which perceiver and provider share a common social identity (Haslam, O’Brien, Jetten, Vormedal, \& Penna, 2005). A common social identity can be derived from viewing another person as a member of one's social group, and can be a lens through which judgements about individuals, social interactions, and demanding situations are made (Haslam, Jetten, O’Brien, \& Jacobs, 2004). A shared sense of social identity between perceiver and provider has been shown to underpin the giving, receiving, and interpretation of support (Haslam et al., 2004; Haslam et al., 2005), and thus might be a key antecedent of perceived coach support. For example, a coach who is perceived to be from a common social group or who possesses similar values may be viewed by an athlete as someone who will understand their situation and is able to provide appropriate support. Indeed, Lakey, Ross, Butler, and Bentley (1996) 
found that similarity in attitudes and values between perceivers and providers influenced judgements of support.

\section{Aims and Hypotheses}

The first aim of this research was to adopt a univariate generalizability theory approach to provide further evidence of the magnitude of perceiver, provider, and relational components of perceived coach support ${ }^{1}$. The second aim was to adopt a multivariate generalizability theory approach to examine whether coach personality, coach competency, and shared social identity predicted perceived coach support at the perceiver, provider, and relational level of analysis. To isolate perceiver, provider, and relational components in generalizability theory studies, all participants are required to rate the same support providers. Such scenarios can be difficult to find in naturally occurring environments, as it is rare to find contexts in which a significant number of coaches are all well known by all athletes (Rees et al., 2012). We therefore conducted two studies with different designs, but with the same measures. In Study 1, participants rated a selection of well-known soccer coaches. In Study 2, participants rated coaches after watching videos of those coaches discussing their coaching style. As the measures and analyses were the same for both studies, we present all our interpretations in an overall Discussion rather than discussing the results of each study separately. For the univariate analyses, it was hypothesized that we would replicate the findings of Rees et al. (2012) and the relational component would account for a significant amount of variance in perceived coach support. In social psychology, provider agreeableness has been found to be consistently related to perceived support at the relational level (Lakey et al., 2004; Lutz \& Lakey, 2001). It was, therefore, hypothesized that agreeableness would positively predict perceived coach support at the relational level, and that coach competency and shared social identity would positively predict additional variance over and above personality. 


\section{Study 1}

\section{Method}

\section{Participants}

The sample was 56 male university soccer players $\left(M_{\text {age }}=20.5\right.$ years, $\left.S D=2.5\right)$. Each player currently worked with a coach, and on average trained for four hours per week $(S D=1.7)$, played two matches per week $(S D=0.6)$, and had played soccer for 14.4 years $(S D=2.7)$

\section{Materials and Procedures}

The study was approved by an institutional ethics review committee and participants provided informed consent. Participants rated five coaches from the English soccer Premier League as potential support providers (cf. Rees et al., 2012) ${ }^{2}$. Participants also completed measures of coach personality, coach competency, and social identity. Participants reported a moderate knowledge $(n=18)$ or a detailed knowledge $(n=38)$ of the coaches ${ }^{3}$.

The five coaches $\left(M_{\mathrm{age}}=60.0\right.$ years, $\left.S D=8.5\right)$ were of different nationalities, had managed in the English Premier League for at least three years, and had all won at least one major domestic trophy in England. Even though the participants had no direct interaction with the coaches, this method of rating perceived support of well-known individuals has been applied in previous research in both social (Lakey et al., 2004) and sport (Rees et al., 2012) psychology. Using well-known individuals as hypothetical support providers has similar characteristics to asking participants to rate members of their own social networks because perceivers will have observed support providers in different situations and displaying various supportive behaviors (Lakey et al., 2004). Indeed, Lakey, Cooper, Cronin, and Whitaker (2014) recently demonstrated that empirical findings are very similar when participants rate symbolic providers (known only through the media or from watching video clips) as to when participants rate support providers from their own network. 
To maintain anonymity and confidentiality, we implemented a similar procedure to previous research (Lakey, McCabe, Fisicaro, \& Drew, 1996; Rees et al., 2012). Participants were presented with a photograph and name of each coach, alongside a unique code which was created by a research assistant. This information was in a separate booklet to the questionnaires. Upon completion, questionnaires were returned in a sealed envelope. The research assistant removed the codes and consent forms before returning the collated questionnaires to the investigators. The investigators were therefore unaware of the support ratings of each coach or which participants provided the ratings. The research assistant was not involved in any other aspect of Study 1 . The order in which the coaches were presented to participants was balanced using a Latin square design.

Perceived Coach Support. Perceived coach support was assessed by a nine-item measure (Rees et al., 2012). Rees et al. provided evidence for the content validity and internal consistency of the measure. Participants rated how supportive each coach would be if the participant actually worked with that coach. The measure asked "To what extent do you feel ... [coach’s code] . . . would ..." and sample items included "listen to your concerns?” and “give you moral support?” Participants responded on a 5-point scale from 0 (not at all) to 4 (extremely). In the present study, internal consistency coefficients for the perceiver, provider, and relational components of perceived coach support, respectively, were $.99, .99$, and .94, calculated from formulae presented by Cardinet, Tourneur, and Allal $(1976)^{4}$

Coach Personality. Coach personality was assessed using the Ten-Item Personality Inventory (Gosling, Rentfrow, \& Swann Jr., 2003). Gosling et al. demonstrated that this measure has acceptable convergent and discriminant validity, test-retest reliability, and is a good alternative to longer personality inventories. Two items measured each of the Big-5 personality dimensions: extraversion, agreeableness, conscientiousness, emotional stability, 
and openness to experience. For each item, two personality characteristics were presented concurrently and participants rated the extent to which the characteristics applied to the coach, even if one applied more strongly than another. Participants responded on a 7-point scale from 1 (disagree strongly) to 7 (agree strongly).

Coach Competency. The Coach Competency Scale (Myers, Feltz, Maier, Wolfe, \& Reckase, 2006) was developed as a multidimensional measure to assess technical, motivational, game strategy, and character building competency. Myers et al. provided evidence for the factorial validity of the measure and internal consistency of each subscale. As participants in the present study had to complete measures in relation to each coach, only one subscale was included to minimize the risk of participant fatigue. The six-item technical competency scale was selected, because key roles of coaches are to teach skills and instruct their athletes on correct technique (Myers et al., 2006). The measure asked "To what extent do you feel the coach is competent in his ability to . ..” and sample items included "coach individual athletes on technique?” and “detect skill errors?” Participants responded on a 10point scale from 0 (not at all) to 9 (extremely). Internal consistency coefficients for the perceiver, provider, and relational components of coach competency, respectively, were .99, .98 , and .96.

Social Identity. Two items adapted from Doosje, Ellemers, and Spears (1995) were used to assess the extent to which participants felt they shared a common social identity with each coach. The measure has been noted to be suitable for use with real and ad-hoc groups (Haslam, 2004), and has been used in research examining the links between social identity and social support (Haslam et al., 2005). In the current study, the measure asked "To what extent do you identify with the coach" and "To what extent do you feel a connection with the coach?” Participants responded on a 7-point scale from 0 (do not agree at all) to 6 (agree completely). 


\section{Statistical Analyses}

Univariate generalizability theory focuses on estimating sources of variance.

Although this can be achieved through different statistical methods, consistent with previous research (Lakey et al., 2004), we used variance components analyses with restricted maximum likelihood estimation to determine the magnitude of perceiver, provider, and relational components in all variables. A fully crossed design with random factors was employed. Questionnaire items and providers (coaches) were within-subjects factors, and perceivers (participants) constituted the between-subjects factor. As the perceived coach support and coach competency questionnaires had more than two items, measurement error was reduced by calculating the mean of odd items, and the mean of even items, which were used as two levels of the items factor (Barry, Lakey, \& Orehek, 2007; Lakey et al., 2004; Lakey \& Rhodes, in press). As such, each variance components analysis had a 56 (participants) x 5 (coaches) x 2 (items) design.

The variance components, 95\% confidence intervals, and percentages of variance were computed. The perceiver, provider, and relational components are the key components of interest, and thus the other components (items, perceiver x item, provider x item, and perceiver x provider x item) are not reported, although they were included when calculating the percentages of variance. Components were considered significant if their 95\% confidence intervals did not include zero. The difference between components was considered significant if their 95\% confidence intervals did not overlap.

Multivariate generalizability theory provides a framework to estimate the relationships between variables at the different levels of analysis. Previous research (e.g., Lakey et al., 2004; Veenstra et al., 2011) has often employed mGENOVA to conduct these analyses, but this doesn't lend itself to examining the incremental effects of multiple independent variables. As such, we followed the steps described by Lakey and Rhodes (in 
press. We first calculated perceiver, provider, and relational component scores for each variable using the formulae presented in Kenny’s (1994) Social Relations Model. For each variable, a perceiver component score was a perceiver's mean score across all providers. A provider component score was a provider's mean score from all perceivers. A relational component score was the score given by a particular perceiver to a provider minus the corresponding perceiver and provider component scores plus the grand mean for that variable. Correlations between perceived coach support and the other variables for each component were then calculated using SPSS version $20.0^{5}$. Following Lakey and Scoboria's (2005) guidelines, however, where components were non-significant at the univariate level for any variable, multivariate analyses involving that component were not calculated. Multiple hierarchical regression analyses were conducted to examine whether coach personality, coach competency, and social identity predicted perceived coach support at the different levels of analysis. As previous generalizability research has demonstrated that provider personality is associated with perceived support (Lakey et al., 2004; Lutz \& Lakey, 2001), coach personality was entered at step 1 . Coach competency and social identity were entered at step 2 to examine whether these variables accounted for additional variance in perceived coach support, beyond provider personality. The unit of observations for perceiver, provider, and relational analyses differed, and reflected the number of athletes, coaches, and athlete-coach dyads respectively.

As each participant rated the same five providers, the assumption of independent scores was violated for the relational component. Consistent with previous generalizability research, therefore, 95\% confidence intervals were computed using percentile bootstrapping with 1000 resamples and used to determine statistical significance (Gross, Lakey, Edinger, Orehek, \& Heffron, 2009; Lakey \& Scoboria, 2005; Neely et al., 2006; Veenstra et al., 
2011) ${ }^{6}$. Correlation and regression coefficients were considered significant if their $95 \%$ confidence intervals did not include zero.

\section{Results}

\section{Univariate Analyses}

The percentage of variance accounted for by the perceiver, provider, and relational components in all variables are presented in Table 1. The relational component accounted for the largest amount of variance in perceived coach support (38\%), but the perceiver component was also significant (19\%). The relational component, 95\% CI [0.12, 0.25], did not, however, account for a significantly greater amount of variance in perceived coach support than the perceiver component, $[0.03,0.16]$. The relational component accounted for a significant amount of variance in all of the other variables, except conscientiousness. The perceiver component accounted for a significant amount of variance in openness to experience, coach competency, and social identity. The provider component was not significant for any of the variables, although this may be because of a lack of statistical power given there were only five providers.

\section{Multivariate Analyses}

Following the significant univariate results, multivariate analyses were only conducted at the perceiver and relational levels. At the perceiver level, coaches who were rated as competent and having a common social identity with the athletes were perceived as supportive (see Table 2). At the relational level, if a coach was rated as particularly agreeable, emotionally stable, open to experience, competent, and having a common social identity by an athlete, that coach was perceived as particularly supportive compared to how that athlete rated other coaches and how the coach was perceived by other athletes. The results from the hierarchical regression analyses are presented in Table 3. At the perceiver level, openness to experience did not account for a significant amount of the variance in 
perceived coach support. Coach competency and social identity collectively accounted for a significant additional amount of variance in perceived coach support. Only social identity, however, contributed significantly to the final model, $b=0.14$, 95\% CI [0.06, 0.23].

At the relational level, extraversion, agreeableness, emotional stability, and openness to experience collectively accounted for a significant amount of variance in perceived coach support. Coach competency and social identity accounted for a significant additional amount of variance. Only agreeableness, coach competency, and social identity contributed significantly to the final model, $b \mathrm{~s}=0.11-0.13,95 \%$ CI $[0.05,0.20]$.

\section{Study 2}

\section{Method}

\section{Participants}

Fifty university athletes (27 females, 23 males; $M_{\text {age }}=20.6$ years, $S D=0.9$ ), from a range of team sports participated in the study. On average, participants trained for five hours per week $(S D=3.6)$, played one competitive match per week $(S D=0.70)$, and had played their sport for 10.1 years $(S D=5.4)$.

\section{Materials and Procedures}

The study was approved by an institutional ethics review committee and participants provided informed consent. We first created five two-to-three minute video clips, each consisting of a different coach describing his/her coaching style (cf. Rees et al., 2012). Coaches were asked to focus on their current approach with athletes, rather than any ideal coaching style or planned behaviour. An independent researcher then reviewed the videos to ensure that they were similar in terms of their length and focus. Participants subsequently viewed each video and completed the same measures as Study 1, although the question stems were adapted so that they referred to the coach in the video participants had viewed. The 
order the coaches were presented to the participants was controlled for by applying a Latin square design.

The coaches $\left(M_{\text {age }}=37.2\right.$ years, $\left.S D=9.8\right)$ had an average of 10.8 years $(S D=5.8)$ experience of coaching team sports and all held a nationally recognized coaching qualification. Thirty nine of the athletes reported having no prior knowledge of any of the coaches. Some participants, however, reported having a little $(n=9)$ or moderate $(n=2)$ knowledge of one coach. Internal consistency reliabilities for the perceiver, provider, and relational components of perceived coach support, respectively, were .99, .99, and .96; and $.99, .99$, and .98 for coach competency.

\section{Statistical Analyses}

Univariate and multivariate analyses replicated those conducted in Study 1.

\section{Results}

\section{Univariate Analyses}

Only the relational component accounted for a significant amount of variance in perceived coach support (46\%; see Table 1$)$. The relational component also accounted for a significant amount of variance in all of the other variables. The perceiver and provider components were not significant for any variables.

\section{Multivariate Analyses}

Following the significant univariate results, multivariate analyses were only conducted at the relational level. If an athlete rated a coach as being particularly extraverted, agreeable, conscientious, emotionally stable, open to experience, competent, and having a common social identity, that coach was perceived as highly supportive (see Table 2).

In the hierarchical regression analysis (see Table 3), the Big-5 personality dimensions collectively accounted for a significant amount of variance in perceived coach support at the relational level. Coach competency and social identity accounted for a significant additional 
amount of variance in perceived coach support. Extraversion, agreeableness, conscientiousness, openness to experience, coach competency, and social identity all contributed significantly to the final model, $b s=0.06-0.20,95 \%$ CI $[0.01,0.24]$.

\section{Discussion}

The purpose of the present research was to apply univariate and multivariate generalizability theory to examine perceived coach support and its antecedents at perceiver, provider, and relational levels of analysis. As hypothesized, the univariate analyses demonstrated that the relational component accounted for a significant amount of variance in perceived coach support. This result highlights that the athletes systematically disagreed in their ratings of the supportiveness of the different coaches. The multivariate analyses demonstrated that there was consistent evidence across the two studies that agreeableness, coach competency, and social identity significantly predicted perceived coach support at the relational level. That is, when athletes perceived specific coaches to be highly agreeable, competent, and sharing a common identity, they also perceived those same coaches to be particularly supportive in comparison to how those athletes rated other coaches and how those coaches were perceived by other athletes.

Consistent with evidence from both sport (Rees et al., 2012) and social (Branje, Van Aken, \& Van Lieshout, 2002; Lakey et al., 2004) psychology, the findings from the current studies highlight the importance of the relational component of perceptions of support suggesting that athletes systematically disagreed in their perceptions of coach support. That is, a particularly supportive coach was perceived more favourably by an athlete compared to how that athlete rated other coaches and how that coach was perceived by other athletes. The relational component was also significant for perceptions of coach personality, competency, and social identity. In Study 1, a behavioral mechanism could potentially explain these findings. Athletes may have disagreed on the personality, competency, social identity, and 
supportiveness of the coaches because they had seen different media coverage and therefore observed unique behaviors from the coaches. The findings, however, were replicated in Study 2, which suggests that a cognitive explanation for the significant relational components may be more plausible (Lakey, 2010). Even when all athletes are exposed to the same coach behaviors in Study 2, they may have interpreted those behaviors differently and formed diverse perceptions of the coaches. For example, one athlete may have viewed a coach's behaviors as friendly, and perceived this coach to be agreeable and supportive. In contrast, another athlete may have viewed the same coach's behaviors as insincere, and perceived the coach to be disagreeable and unsupportive.

Beyond the univariate analyses, our aim was to extend understanding by examining antecedents of perceived coach support. Indeed, the present research is the first to employ a multivariate generalizability theory approach to examine these effects in sport. Congruent with previous research in social psychology (Lakey et al., 1999; Lutz \& Lakey, 2001), the multivariate analyses demonstrated that the personality of the support provider (in particular agreeableness), was related to perceived coach support at the relational level. Such evidence is consistent with social cognitive explanations for how perceptions of support are formed. Lakey and Drew (1997) argued that perceptions of supportiveness are derived from generic evaluations of the providers or their specific traits.

Unique to this study, we also demonstrated that coach competency and a common social identity were significantly associated with perceptions of support at the relational level, over and above the effect of coach personality. The importance of coach competency complements research which has demonstrated that coaches' experience, reputations, and qualifications are important factors that influence athletes’ judgments about them (Manley et al., 2008), and that provider knowledge and expertise are key factors in influencing perceptions of support (Gottlieb, 2000; Rosenfeld et al., 1989). Our results also build on 
previous work in social psychology that has noted the importance of social identity in influencing judgments of support (Haslam et al., 2004; Haslam et al., 2005). Levine et al. (2005) examined the role of identity in emergency helping and found that supportive acts were interpreted in the intended way when perceivers and providers shared a common social identity. By applying a generalizability theory approach, the current research extends understanding by demonstrating that athletes systematically disagreed in their perceptions of coach competency and social identity, and that these disagreements were associated with athletes having different perceptions of coach support. Importantly, these findings were robust regardless of whether all athletes had been exposed to the same coach behaviors (Study 2) or not (Study 1).

The results highlighted in the previous paragraph are important for at least two key reasons. First, the present results highlight the utility of employing multivariate generalizability theory as a framework for exploring factors that are related to perceived coach support. A distinct advantage of applying multivariate generalizability theory is that these correlates of perceived coach support can be partitioned into perceiver, provider, and relational components (Lakey \& Orehek, 2011), and the relationships between perceptions of support and its correlates can vary across the different components (Lakey, 2010). For example, in the present studies, openness to experience was significantly correlated with perceived coach support at the relational level but not at the perceiver level. Applying multivariate generalizability theory thus enables a more fine-grained conceptual understanding of the correlates of perceived coach support. Second, the significant relational results imply systematic disagreement and that the effects for predictors of support in large sample studies may be far from universal. This implies that when studies are conducted without taking into account perceiver, provider, and relational components, they are likely to risk losing valuable information. 
In terms of the application of this work to practice, the comments raised in the previous paragraph may shed light on the apparent inconsistencies observed when interventions attempt to increase perceptions of support (Brand, Lakey, \& Berman, 1995; Hogan, Linden \& Najarian, 2002), normally by introduction of one professional provider. For example, the introduction of a single supportive community staff worker to all elderly women in a ten week support intervention did not lead to increased perceived support (Heller, Thompson, Trueba, Hogg, \& Vlachos-Weber, 1991). In sport, the current findings suggest that if one new coach is introduced to a team, members of that team will disagree over the supportiveness of the coach. The relational effects observed in the present research suggest that interventions with the goal to optimize perceptions of coach support might consider matching athletes with coaches whom they perceive as agreeable and competent, and with whom they identify (Lakey, 2010; Veenstra et al., 2011). This matching approach, however, could be time consuming and may not be feasible in all sports or contexts, such as where a team has only one coach.

An alternative to this matching approach would be to attempt to enhance athletes' perceptions of coach agreeableness, competency, or common social identity. As all of these variables predicted perceived coach support at the relational level, it would seem reasonable to target any of these variables for intervention. We would argue, however, that a focus on social identity may be more likely to yield the most beneficial impact. Both the personality (Branje, van Lieshout, \& Gerris., 2007; McCrae \& Costa Jr., 1994) and the competency (Manley et al., 2008) of the coach are relatively stable constructs, offering limited opportunity for change. In contrast, by harnessing an understanding of social identity, coaches could help cultivate a common social identity between them and their athletes, which could help to promote their athletes’ perceptions of them as supportive coaches. For example, coaches could work with athletes on an individual basis to emphasize values that 
they share or groups to which they both belong. If coaches foster a strong common identity with individual athletes, it could underpin supportive coach-athlete dyads.

Against the backdrop of the contributions this paper makes to understanding the support process in sport, potential limitations of the current research should be noted. First, as all variables were assessed contemporaneously, causality cannot be inferred. Second, perceiver, provider, and relational effects were derived from different numbers of observations due to unequal number of athletes, coaches, and dyads. These differences may have influenced the findings, particularly the power to detect a significant provider component. Third, participants were asked to rate either well-known coaches (Study 1) or unknown coaches in two-to-three minute video clips (Study 2). The participants did not rate support providers from their own social network. Although the practice of using well-known providers and videos has been successfully applied in previous social support research (Rees et al., 2012; Veenstra et al., 2011), this approach could be criticized on grounds of ecological validity. However, the ability to isolate perceiver, provider, and relational components, requires all participants to rate the same providers. This leads to difficulty in finding naturalistic contexts in which a sufficient number of providers are well known to all participants (Lakey et al., 2004), which may limit the wider use of generalizability theory approaches with fully crossed designs. A potential future avenue is to ask athletes to focus upon support from coaches within their existing support network. What this design brings in terms of ecological validity, it loses, however, in terms of specificity. In this design, termed partially nested, each participant would rate different providers and the provider and relational components could not be separated. Despite its limitations, we believe this approach may offer a useful avenue for future research.

In conclusion, the present research provides further evidence of the importance of examining the relative contribution of perceiver, provider, and relational components of 
perceived coach support, as well as a novel insight into the factors which are related to perceived coach support at each of those levels. The key contributor to both perceptions of coach support and its correlates was the relational component. This suggests that not only do athletes differ in their perceptions of the same coach as being more or less supportive than other coaches, they also differ in the extent to which they perceive those same coaches to be agreeable, competent, and sharing of a common social identity. Importantly, the findings demonstrate that athletes-differ in perceiving certain coaches as highly agreeable, competent, and sharing a common identity with them, and predict their perceptions of those same coaches as being more supportive than others. Thus, by applying a multivariate generalizability theory approach, these studies have been able to provide a more detailed understanding of factors which are associated with perceived coach support.

\section{Acknowledgements}

The authors thank Jaye Moore-Smith and Sarah Veitch for their help creating the videos used in Study 2 and for their assistance during data collection. 


\section{References}

Alvarez, M. S., Balaguer, I., Castillo, I., \& Duda, J. L. (2009). Coach autonomy support and quality of sport engagement in young soccer players. The Spanish Journal of Psychology, 12, 138-148. doi:10.1017/S1138741600001554

Antonini Philippe, R., \& Seiler, R. (2006). Closeness, co-orientation and complementarity in coach-athlete relationships: What male swimmers say about their male coaches. Psychology of Sport and Exercise, 7, 159-172. http://dx.doi.org/10.1016/j.psychsport.2005.08.004

Bakker, A. B., Oerlemans, W., Demerouti, E., Slot, B. B. \& Ali, D. M. (2011). Flow and performance: A study among talented Dutch soccer players. Psychology of Sport an Exercise, 12, 442-450. http://dx.doi.org/10.1016/j.psychsport.2011.02.003

Barry, R., Lakey, B., \& Orehek, E. (2007). Links among attachment dimensions, affect and the self for broadly-generalized attachment styles and relationship-specific bonds. Personality and Social Psychology Bulletin, 33, 240-253. doi:10.1177/0146167206296102

Bianco, T. (2001). Social support and recovery from sport injury: Elite skiers share their experiences. Research Quarterly for Exercise and Sport, 72, 376-388.

Bianco, T., \& Eklund, R. C. (2001). Conceptual considerations for social support research in sport and exercise settings: The case of sport injury. Journal of Sport \& Exercise Psychology, 23, 85-107.

Bolger, N., Foster, M., Amiram, V. D. \& Ng, R. (1996). Close relationships and adjustment to a life crisis: The case of breast cancer. Journal of Personality and Social Psychology, 70, 283-94. doi: 10.1037/0022-3514.70.2.283 
Brand, E. F., Lakey, B., \& Berman, S. (1995). A preventive, psychoeducational approach to increase perceived social support. American Journal of Community Psychology, 23, 117-135. doi: 10.1007/BF02506925

Branje, S. J .T., van Aken, M. A. G., \& van Lieshout, C. F. M. (2002). Relational support in families with adolescents. Journal of Family Psychology, 16, 351-362. doi:10.1037/0893-3200.16.3.351

Branje, S. J. T., van Lieshout, C. F. M., \& Gerris, J. R. M. (2007). Big Five personality development in adolescence and adulthood. European Journal of Personality, 21, 4562. doi:10.1002/per.596

Cardinet, J., Tourneur, T., \& Allal, L. (1976). The symmetry of generalizability theory: Application to educational measurement. Journal of Educational Measurement, 13, 119-135.

Chelladurai, P. \& Saleh, S. D. (1980). Dimensions of leader behaviour in sports: Development of a leadership scale. Journal of Sport Psychology, 2, 34-45.

Chiaburu, D., van Dam, K., \& Hutchins, H. (2010). Social support in the workplace and training transfer: a longitudinal analysis. International Journal of Selection and Assessment, 18, 187-200. doi: 10.1111/j.1468-2389.2010.00500.x

Cohen, S., \& Janicki-Deverts, D., (2009). Can we improve our physical health by altering our social networks? Perspectives on Psychological Science. 4, 375-378. doi: 10.1111/j.1745-6924.2009.01141.x

Connaughton, D., Wadey, R., Hanton, S., \& Jones, G. (2008). The development and maintenance of mental toughness: Perceptions of elite performers. Journal of Sports Sciences, 26, 83-95. doi:10.1080/02640410701310958 
Cronbach, L. J., Gleser, G. C., Nanda, H., \& Rajaratnam, N. (1972). The dependability of behavioural measurements: Theory of generalizability for scores and profiles. NewYork: Wiley.

DeFreese, J. D., \& Smith, A. L. (2013). Teammate social support, burnout, and selfdetermined motivation in collegiate athletes. Psychology of Sport \& Exercise, 14, 258-265. doi:10.1016/j.psychsport.2012.10.009

Doosje, B., Ellemers, N., \& Spears, R. (1995). Perceived intragroup variability as a function of group status and identification. Journal of Experimental Social Psychology, 31, 410-436. doi: 10.1006/jesp.1995.1018

Ertel, K. A., Glymour, M. M., \& Berkman. L. F. (2009). Social networks and health: A life course perspective integrating observational and experimental evidence. Journal of Social and Personal Relationships, 26, 73-92.

Fletcher, D., \& Sarkar, M. (2012). A grounded theory of psychological resilience in Olympic champions. Psychology of Sport \& Exercise, 13, 669-678. http://dx.doi.org/10.1016/j.psychsport.2012.04.007

Freeman, P., \& Rees, T. (2008). The effects of perceived and received support upon objective performance outcome. European Journal of Sport Science, 8, 359-368. doi: $10.1080 / 17461390802261439$

Freeman, P., \& Rees, T. (2009). How does perceived support lead to better performance? An examination of potential mechanisms. Journal of Applied Sport Psychology, 21, 429441. doi:10.1080/10413200903222913

Gillet, N., Vallerand, R. J., Amoura, S., \& Baldes, B. (2009). Influence of coaches' autonomy support on athletes' motivation and sport performance: a test of the hierarchical model of intrinsic and extrinsic motivation. Psychology of Sport and Exercise, 11, 155-161. http://dx.doi.org/10.1016/j.psychsport.2009.10.004 
Gosling, S. D., Rentfrow, P. J., \& Swann Jr., W. B. (2003). A very brief measure of the BigFive personality domains. Journal of Research in Personality, 37, 504-528. doi:10.1016/S0092-65660300046-1

Gottlieb, B. H. (2000). Selecting and planning support interventions. In S. Cohen, L. G. Underwood, \& B. H. Gottlieb (Eds.), Social support measurement and intervention: A guide for health and social scientists (pp. 195-220). New York: Oxford University Press.

Gross, J., Lakey, B., Edinger, K., Orehek, E., \& Heffron, D. (2009). Person perception in the college classroom: Accounting for tastes in students’ evaluations of teaching effectiveness. Journal of Applied Social Psychology, 39, 1609-1638. doi:10.1111/j.1559-1816.2009.00497.x

Haber, M. G., Cohen, J. L., Lucas, T., \& Baltes, B. B. (2007). The relationship between selfreported received and perceived social support: A meta-analytic review. American Journal of Community Psychology, 39, 133-144. doi: 10.1007/s1046400791009

Haslam, S. A. (2004). Psychology in organizations: The social identity approach (2nd ed.). London, England: Sage.

Haslam, S. A., Jetten, J., O'Brien, A., \& Jacobs, E. (2004). Social identity, social influence and reactions to potentially stressful tasks: support for the self-categorization model of stress. Stress and Health, 20, 3-9. doi:10.1002/smi.995

Haslam, S. A., O'Brien, A., Jetten, J., Vormedal, K., \& Penna, S. (2005). Taking the strain: Social identity, social support, and the experience of stress. British Journal of Social Psychology, 44, 355-370. doi:10.1348/014466605x37468

Heller, K., Thompson, M. G., Trueba, P. E., Hogg, J. R., \& Vlachos-Weber, I. (1991). Peer support telephone dyads for elderly women: Was this the wrong intervention? American Journal of Community Psychology, 19, 53-74. 
Hogan, B. E., Linden, W., \& Najarian, B. (2002). Social support interventions. Do they work? Clinical Psychology Review, 22, 381-440. http://dx.doi.org/10.1016//S02727358(01)00102-7

Horn, T. S. (2002). Coaching effectiveness in the sports domain. In T. S. Horn (Ed.), Advances in sport psychology (pp. 309-354). Champaign, IL: Human Kinetics.

Judge, L. W., Bellar, D., Blom, L. C., Lee, D., Harris, B., Turk, M., McAtee, G., \& Johnson, J. (2012). Perceived social support from strength and conditioning coaches among injured student athletes. Journal of Strength and Conditioning Research, 26, 1154 1161. doi: 10.1519/JSC.0b013e31822e008b

Kenny, D. A. (1994). Interpersonal perception: A social relations analysis. New York: Guilford Press.

Kristiansen, E., \& Roberts, G. C. (2010). Young elite athletes and social support: Coping with competitive and organizational stress in "Olympic" competition. Scandinavian Journal of Medicine and Sport Science, 20, 686-695. doi:10.1111/j.16000838.2009.00950.x

Lakey, B. (2010). Basic research in social support suggests new strategies for intervention. In J. E. Maddux \& P. Tangey (Eds.), Social psychological foundations of clinical psychology (pp. 177-194). New York: Guildford Publications.

Lakey, B., Cohen, J. L., \& Neely, L. C. (2008). Perceived support and relational effects in psychotherapy process constructs. Journal of Counseling Psychology, 55, 209-220. doi: 10.1037/0022-0167.55.2.209

Lakey, B., Cooper, C., Cronin, A., \& Whitaker, T. (2014). Symbolic providers help people regulate affect relationally: Implications for perceived support. Personal Relationships, 20, 404-419. DOI: 10.1111/pere.12038 
Lakey, B. \& Drew, J. B. (1997). A social-cognitive perspective of social support. In G. R. Pierce, B. Lakey, I. G. Sarason \& B. R. Sarason (Eds.), Sourcebook of social support and personality, (pp. 107-140). NY: Plenum.

Lakey, B., Drew, J. B., \& Sirl, K. (1999). Clinical depression and perceptions of supportive others: A generalizability analysis. Cognitive Therapy and Research, 23, 511-533. doi:10.1023/a:1018772421589

Lakey, B., McCabe, K., Fisicaro, S., \& Drew, J. (1996). Personal and environmental determinants of social support: Three generalizability studies. Journal of Personality and Social Psychology, 70, 1270-1280. doi: 10.1037/0022-3514.70.6.1270

Lakey, B. \& Orehek, E. (2011). Relational regulation theory: A new approach to explain the link between perceived social support and mental health. Psychological Review, 118, 482-495. doi:10.1037/a0023477

Lakey, B., \& Rhodes, G. (in press). The social regulation of affect and self-esteem among opiate dependent adults. Personal Relationships.

Lakey, B., Ross, L. T., Butler, C., \& Bentley, K. (1996). Making social support judgments: The role of similarity and conscientious. Journal of Social and Clinical Psychology, 15, 283-304.

Lakey, B., \& Scoboria, A. (2005). Trait and social influences in the links among perceived social support, affect and self-esteem. Journal of Personality, 73, 361-388. doi.10.1111/j.1467-6494.2005.00312.x

Lutz, C. J., \& Lakey, B. (2001). How people make support judgments: Individual differences in the traits used to infer supportiveness in others. Journal of Personality and Social Psychology, 81, 1070-1079. doi:10.1037/0022-3514.81.6.1070 
Levine, R. M., Prosser, A., Evans, D. \& Reicher, S.D. (2005). Identity and emergency intervention: How social group membership and inclusiveness of group boundaries shapes helping behavior. Personality and Social Psychology Bulletin, 31, 443-453.

Mageau, G. A., \& Vallerand, R. J. (2003). The coach-athlete relationship: A motivational model. Journal of Sports Sciences, 21, 883-904. doi:10.1080/0264041031000140374

Manley, A. J., Greenlees, I., Thelwell, R., Filby, W. C. D., \& Smith, M. J. (2008). Athletes perceived sources of information sources when forming initial impressions and expectancies of a coach: An exploratory study. The Sport Psychologist, 22, 73-89.

McCrae, R. R., \& Costa Jr., P. T. (1994). The stability of personality: Observations and evaluations. Current Directions in Psychological Science, 3, 173-175. doi:10.1111/1467-8721.ep10770693

Myers, N. D., Feltz, D. L., Maier, K. S., Wolfe, E. W., \& Reckase, M. D. (2006). Athletes' evaluations of their head coach's coaching competency. Research Quarterly for Exercise and Sport, 77, 111-121. doi.10.1080/02701367.2006.10599337

Neely, L. C., Lakey, B., Cohen, J. L., Barry, R., Orehek, E., Abeare, C. A., et al. (2006). Trait and social processes in the link between social support and affect: An experimental laboratory investigation. Journal of Personality, 74, 1015-1046. doi: 10.1111/j.14676494.2006.00401.x

Rees, T., \& Freeman, P. (2007). The differential impact of perceived and received support upon confidence. Journal of Sports Sciences, 25, 1057-1065. doi.10.1080/02640410600982279

Rees, T., Freeman, P., Bell, S., \& Bunney, R. (2012). Three generalizability studies of the components of perceived coach support. Journal of Sport \& Exercise Psychology, 34, 238-251. 
Rees, T., \& Hardy, L. (2000). An investigation of the social support experiences of high-level sport performers. The Sport Psychologist, 14, 327-347.

Rees, T., Ingledew, D. K., \& Hardy, L. (1999). Social support dimensions and components of performance in tennis. Journal of Sports Sciences, 17, 421-429. doi.10.1080/026404199365948

Rosenfeld, L. B., Richman, J. M., \& Hardy, C. J. (1989). Examining social support networks among athletes: Description and relationship to stress. The Sport Psychologist, 3, 2333.

Schwarzer, R., \& Knoll, N. (2007). Functional roles of social support within the stress and coping process: A theoretical and empirical overview, International Journal of Psychology, 42, 243-252. 10.1080/00207590701396641

Smoll, F. L., \& Smith, R. E. (1989). Leadership behaviors in sport: A theoretical model and research paradigm. Journal of Applied Social Psychology, 19, 1522-1551. doi:10.1111/j.1559-1816.1989.tb01462.x

Stambulova, N., Alfermann, D., Statler, T., \& Côté, J. (2009). Career development and transitions of athletes: The ISSP position stand. International Journal of Sport \& Exercise Psychology, 7, 395-412. doi:10.1080/1612197X.2009.9671916

Thelwell, R., Weston, N., Greenlees, I., Page, J., \& Manley, A. (2010). Examining the impact of physical appearance on impressions of coaching competence. International Journal of Sport Psychology, 41, 277-292.

Thoits, P. A. (2011). Mechanisms linking social ties and support to physical and mental health. Journal of Health and Social Behavior, 52, 145-161. doi: $10.1177 / 0022146510395592$

Uchino, B. N. (2004). Social support and physical health: Understanding the health consequences of our relationships. New Haven, CT: Yale University Press. 
Uchino, B. N. (2009). Understanding the links between social support and physical health: A lifespan perspective with emphasis on the separability of perceived and received support. Perspectives in Psychological Science, 4, 236-255. doi.10.1111/j.17456924.2009.01122.x

Umberson, D., \& Montez, J. K. (2010). Social relationships and health: A flashpoint for health policy. Journal of Health and Social Behavior, 51, 54-66. doi: $10.1177 / 0022146510383501$

Vangelisti, A. L. (2009). Challenges in conceptualising social support, Journal of Social and Personal Relationships. 26, 39-51. doi:10.1177/0265407509105520

Veenstra, A. L., Lakey, B., Cohen, J. L., Neely, L. C., Orehek, E., Barry, R., \& Abeare, C. A. (2011). Forecasting the specific providers that recipients will perceive as unusually supportive. Personal Relationships, 18, 1-20. doi:10.1111/j.1475-6811.2010.01340.x

Yu, C. H., (2001). An introduction to computing and interpreting Cronbach Coefficient Alpha in SAS. Proceedings of $26^{\text {th }}$ SAS User Group International Conference. 


\section{Footnotes}

${ }^{1}$ Perceived coach support was our primary interest for univariate analysis, therefore, no specific hypotheses were made regarding the variance components of coach personality, coach competence, and social identity.

${ }^{2}$ There was no overlap in the participants of Study 1 and 2, or with those who participated in Rees et al. (2012). Further, two of the five coaches used in Study 1 were included in Rees et al. (2012).

${ }^{3}$ To examine whether knowledge of coaches influenced the amount of variance accounted for by perceiver, provider, and relational components in all variables, the univariate analyses for Study 1 were repeated including only participants who had a detailed knowledge of all coaches. Similarly, the univariate analyses in Study 2 were repeated including only participants who had no prior knowledge of any coaches. These additional analyses found a similar pattern of results to those which included all of the participants.

${ }^{4}$ According to Yu (2001) a reliability coefficient should only be calculated when using measures consisting of three or more items, so a reliability coefficient was not calculated for coach personality and social identity.

${ }^{5}$ To determine the consistency of our approach with that used in previous studies, we also calculated the correlations between perceived coach support and the other variables reported in Study 1 using mGENOVA. An intraclass correlation coefficient of .96 suggested a high level of absolute agreement between the two approaches. Full details of these analyses can be obtained from the first author.

${ }^{6}$ Given the existence of different methods of bootstrapping, we reran the relational analyses (correlations and hierarchical regression) using a block bootstrapping approach. The standard errors produced were very similar to those reported in the manuscript and did not alter the 
significance of any statistic in Study 1 or 2. Full details of these additional analyses can be obtained from the first author. 
Table 1

Percentages of variance accounted for by each component in perceived coach support, coach personality, coach competency, and social identity.

\begin{tabular}{lcccccc}
\hline \multirow{2}{*}{\multicolumn{1}{c}{ Variable }} & \multicolumn{2}{c}{ Perceiver } & \multicolumn{2}{c}{ Provider } & \multicolumn{2}{c}{ Relational } \\
\cline { 2 - 7 } & Study 1 & Study 2 & Study 1 & Study 2 & Study 1 & Study 2 \\
\hline Perceived coach support & $19.3^{*}$ & 8.3 & 16.0 & 27.4 & $38.2^{*}$ & $46.3^{*}$ \\
Extraversion & 6.5 & 1.3 & 11.8 & 22.2 & $17.5^{*}$ & $29.0^{*}$ \\
Agreeableness & 0.6 & 0.3 & 6.4 & 16.7 & $16.4^{*}$ & $29.8^{*}$ \\
Conscientiousness & 11.2 & 3.2 & 2.6 & 7.5 & 7.7 & $25.4^{*}$ \\
Emotional stability & 1.8 & 3.6 & 1.2 & 9.5 & $25.3^{*}$ & $11.8^{*}$ \\
Openness to experience & $13.7^{*}$ & 0.0 & 0.4 & 22.7 & $17.3^{*}$ & $37.4^{*}$ \\
Coach competency & $46.2^{*}$ & $15.5^{*}$ & 1.3 & 19.6 & $36.7^{*}$ & $56.9^{*}$ \\
Social identity & $15.9^{*}$ & $13.1^{*}$ & 8.9 & 21.6 & $43.5^{*}$ & $46.6^{*}$ \\
\hline
\end{tabular}

Notes. * Significant to $p<.05$. 
Table 2

Correlations between the components scores of perceived coach support and coach personality, coach competency, and social identity.

\begin{tabular}{ccccc}
\hline Variable & \multicolumn{2}{c}{ Perceiver } & \multicolumn{2}{c}{ Relational } \\
& Study 1 & Study 2 & Study 1 & Study 2 \\
\hline Extraversion & - & - & .11 & $.41^{*}$ \\
Agreeableness & - & - & $.39^{*}$ & $.43^{*}$ \\
Conscientiousness & - & - & - & $.43^{*}$ \\
Emotional stability & - & - & $.29^{*}$ & $.31^{*}$ \\
Openness & .26 & - & $.16^{*}$ & $.53^{*}$ \\
Coach competency & $.34^{*}$ & - & $.42^{*}$ & $.51^{*}$ \\
Social identity & $.45^{*}$ & - & $.48^{*}$ & $.59^{*}$ \\
\hline
\end{tabular}

Notes. * Significant to $p<.05$ using percentile bootstrapping with 1000 resamples.

Correlations were not calculated for components that were non-significant in the univariate analyses. The provider component was not included due to non-significant univariate results for all variables. 
Table 3

Hierarchical regression analyses for predicting perceiver and relational components of perceived coach support.

\begin{tabular}{|c|c|c|c|c|c|c|}
\hline Study & Component & Step & Variable & $\Delta R^{2}$ & $b$ & $95 \%$ CI \\
\hline \multirow[t]{3}{*}{1} & Perceiver & 1 & Openness & .07 & 0.06 & {$[-0.04,0.16]$} \\
\hline & & 2 & Competency & $.20 *$ & 0.08 & {$[-0.04,0.15]$} \\
\hline & & & Social identity & & $0.14^{*}$ & {$[0.06,0.23]$} \\
\hline \multirow[t]{6}{*}{1} & Relational & 1 & Extraversion & $.22 *$ & 0.05 & {$[-0.01,0.09]$} \\
\hline & & & Agreeableness & & $0.13^{*}$ & {$[0.07,0.19]$} \\
\hline & & & Emotional stability & & 0.03 & {$[-0.01,0.08]$} \\
\hline & & & Openness & & 0.00 & {$[-0.05,0.06]$} \\
\hline & & 2 & Competency & $.17^{*}$ & $0.13 *$ & {$[0.05,0.20]$} \\
\hline & & & Social identity & & $0.11^{*}$ & {$[0.07,0.15]$} \\
\hline \multirow[t]{7}{*}{2} & Relational & 1 & Extraversion & $.52 *$ & $0.08^{*}$ & {$[0.04,0.13]$} \\
\hline & & & Agreeableness & & $0.20 *$ & {$[0.15,0.24]$} \\
\hline & & & Conscientiousness & & $0.11^{*}$ & {$[0.04,0.17]$} \\
\hline & & & Emotional stability & & -0.01 & {$[-0.07,0.05]$} \\
\hline & & & Openness & & $0.06^{*}$ & {$[0.01,0.11]$} \\
\hline & & 2 & Competency & $.07 *$ & $0.09 *$ & {$[0.05,0.14]$} \\
\hline & & & Social identity & & $0.08 *$ & {$[0.02,0.14]$} \\
\hline
\end{tabular}

* Significant to $p<.05$ using percentile bootstrapping with 1000 resamples. $b=$ unstandardized beta value. Hierarchical regression analysis was only conducted with the components that were significant in the univariate analyses. 